\title{
THE UNUSUAL BEHAVIOR OF GIBBS’ REAGENT VERSUS NITROFURAL
}

\author{
Iliyan Kolev', Sonya Ivanova ${ }^{2}$ \\ ${ }^{1}$ Department of Pharmaceutical Sciences and Pharmaceutical Management, \\ Faculty of Pharmacy, Medical University of Varna \\ ${ }^{2}$ Pharmacy "Poly", POLIMEKS LTD, Varna
}

\begin{abstract}
The study covers a new qualitative analytic test (method) for detecting the semicarbazone chemotherapeutic Nitrofural. The combination of Gibbs' reagent and ammonia was successfully implemented for analyzing the drug. The main structural features of the obtained color products were determined by UV-VIS spectroscopy.
\end{abstract}

Keywords: pharmaceutical analysis, Nitrofural, Gibbs' reagent

\section{INTRODUCTION}

Aldehyde hydrazones are a functional class of organic compounds with the general structure R$\mathrm{CH}=\mathrm{N}-\mathrm{NR}$ 'R". The aldehyde hydrazone moiety as a pharmacophoric element is a relatively rarely encountered artificial structural motif.

In the content of the European pharmacopoeia, the presence of this type of functional unit can only be recorded in the composition of the following three representatives:

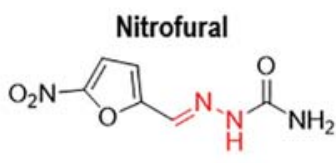

2-[(5-nitrofuran-2yl)methylene]diazanecarboxamide

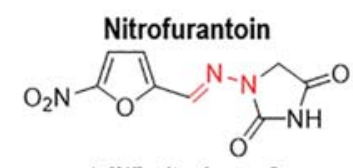

1-[[(5-nitrofuran-2yl)methylene]amino]imidazolidine-2,4-
Being representatives of the nitrofuranic antimicrobial set, these chemotherapeutic agents are usually used for treating uncomplicated urinary tract infections caused by some susceptible pathogens, e.g. Escherichia coli, Staphylococcus aureus, Streptococcus pyogenes, and Aerobacter aerogenes, as well as against some of the not-so-frequently encountered strains of Salmonella and Giardia spp., trichomonads, amebae, and some coccidial species (1).
Address for correspondence:

Iliyan Kolev

Faculty of Pharmacy

Medical University of Varna

84 Tzar Osvoboditel Blvd

9002 Varna

e-mail: ilian.kolev@mu-varna.bg

Received: May 14, 2018

Accepted: May 29, 2018

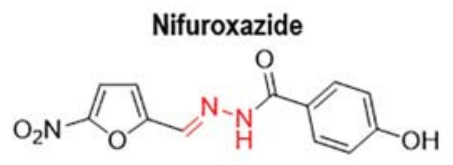

(E)-4-hydroxy-N'-[(5-nitrofuran-2yl)methylidene]benzohydrazide

From an analytical point of view, however, being pharmacopoeial agents, each one of the presented medicaments should be a subject of indisputable qualitative control - a qualitative control, which is designed to give a full confirmation of the chemical structure of the product analyzed in toto or, partially about its peculiar structural element (functionality).

On the whole, the pharmaceutical qualitative analysis is intended to confirm the identity of pharmaceutical raw materials with a so-marked "acceptable" level of security. Thereat, a wide variety of color 
Iliyan Kolev, Sonya Ivanova

reactions and some other types of identity tests were included in the scope of the so-called "second identification" pharmacopoeial analysis.

A real idea of the power of the methods mentioned may be given by certain striking examples: the sensitive pharmacopoeial test for the detections, rapid estimation, and determination of impurities of water-soluble aliphatic aldehydes (formaldehyde, acetaldehyde, glyoxal etc.) in the content of vaccines, Ethylcellulose, and Hydroxyethylcellulose $(2,3)$
Scanty notes on the analytical chemistry of these types of functionalities can be found solely in older and less accessible scientific sources.

Moreover, the analytical comments on these functionalities and their reactivity are opposing to a certain extent. In some of them positive reactions for most aldehyde hydrazones were noted (in an uncertain manner), but not for semicarbazones ${ }^{2}$ or vice versa.

Therefore, the present work discusses the pos-

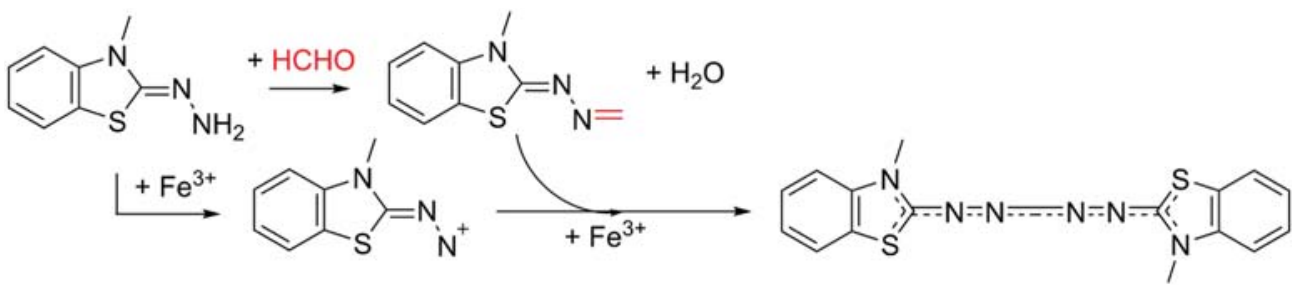

as well as the standardized color test for the identification of Phenazone ${ }^{1}$.<smiles>Cc1cc(=O)n(-c2ccccc2)n1C</smiles>

As to the qualitative analysis of aldehyde hydrazones, and especially of semicarbazonic functional, the absence of any information in the contemporary electronic literature (including pharmacopoeial content) has, unfortunately, been registered. sibilities to use Gibbs' reagent in the quantitative analysis of the semicarbazone moiety of the title compound.

\section{MATERIALS AND METHODS}

All chemicals were of analytical grade and used as received without any further purification: 2,6-Dichloroquinone-4-chloroimide ${ }^{3}$ ( $\geq 95 \%$, Sigma-Aldrich), Nitrofural (98+\%, Alfa Aesar), HCl (37\%, Panreac). The solvents ethanol (anhydrous), DMSO, and dichloromethane were received from Fisher Scientific. All reactions were performed under ambient conditions using standard $2.0 \mathrm{ml}$ screw thread mi-

Table 1. A table illustrating the volume ratio between different solvents used in each experiment

\begin{tabular}{l|c|ccccccc} 
Solution & $\mathrm{AB}$ & $\mathrm{AC}$ & $\mathrm{AD}$ & $\mathrm{ABD}$ & $\mathrm{ABE}$ & $\mathrm{ABC}$ & $\mathrm{ABC1}$ & $\mathrm{ABC} 2$ \\
$\mathbf{A}^{*}$ & $0.5 \mathrm{ml}$ & $0.5 \mathrm{ml}$ & - & $0.5 \mathrm{ml}$ & $0.5 \mathrm{ml}$ & $0.5 \mathrm{ml}$ & $0.5 \mathrm{ml}$ & $0.5 \mathrm{ml}$ \\
$\mathbf{B}^{\star *}$ & $0.5 \mathrm{ml}$ & - & $0.5 \mathrm{ml}$ & $0.5 \mathrm{ml}$ & $0.5 \mathrm{ml}$ & $0.5 \mathrm{ml}$ & $0.5 \mathrm{ml}$ & $0.5 \mathrm{ml}$ \\
$\mathbf{C}$ (ammonia) & - & $0.5 \mathrm{ml}$ & $0.5 \mathrm{ml}$ & - & - & $0.5 \mathrm{ml}$ & $0.05 \mathrm{ml}$ & $0.25 \mathrm{ml}$ \\
$\mathbf{D}(1.0$ M HCl $)$ & - & - & - & $0.25 \mathrm{ml}$ & - & - & - & - \\
$\mathbf{E}$ (water) & - & - & - & - & $0.5 \mathrm{ml}$ & - & - & - \\
\hline \hline
\end{tabular}

${ }^{*} 0.1 \%$ sol. of 2,6-dichloroquinone-4-chloroimide in $\mathrm{CHCl}_{3}$.

${ }^{*} 0.1 \%$ sol. of Nitrofural in DMSO.

\footnotetext{
${ }^{1}$ An analgesic, a nonsteroidal anti-inflammatory and antipyretic drug.
}

${ }^{2}$ Most semicarbazones possess special analytical significance because they crystallize (recrystallize) readily and have sharp melting points (4). ${ }^{3}$ Synonyms: N,2,6-Trichloro-p-benzoquinoneimide, Gibbs reagent. The reagent is named after an American chemist, Harry Drake Gibbs (1872 - 1934). 
crotubes made of transparent polypropylene (Deltalab, Spain).

UV-Vis spectra were taken on an Evolution 220 (Thermo Scientific, USA) spectrophotometer model.

Procedure: Each microtube was loaded with appropriate volumes of solutions A, B, C, D, and E (Table 1), and then sealed with a cap with a silicon $\mathrm{O}$ ring. All tests were repeated three times to confirm the repeatability of the analysis.

Caution!!! All work with chloroform and DMSO must be done under a well-ventilated hood using protective clothing and gloves.

\section{RESULTS AND DISCUSSION}

The Gibbs' reagent has the ability to bind to various different unhindered phenolic structural motifs (5-8), some esters $(9,10)$, certain thiols and sulfhydryl groups (11,12), nitroxyl groups (8), amines (13-15), and some aliphatic and aromatic acid hydrazides, as well as to aldehyde hydrazones (16).

The Gibbs' reagent has been and is still used as a powerful analytical tool for the qualitative and quantitative analysis of many pharmacopoeial representatives, such as orciprenaline sulfate (2), Cresolum crudum (17,18), vitamins B6 (19) and K (20), theophylline (21), methylthiouracil $(22,23)$, the anesthetic propofol (24-26), as well as of some antibiotics and opiates (27). The presence both of all aforementioned compounds and many other non-pharmaco- poeial analytes can also be verified using the "Gibbs' spray" (TLC developer).

In addition to a liquid medium, the reactivity of Gibbs' reagent has been found to be intact both in the solid state and at the so-called point of solvent evaporation (semisolid state).

It is supposed that the mechanism of all foregoing analytical reactions most probably is based on the ability of the Gibbs' reagent to come into direct contact with the active $\mathrm{CH}$ (or $\mathrm{CH}_{2}$ ) functional centers of the tested analytes. The mechanism of the reactions is, however, not so uniform with regard to all participants (including aldehyde hydrazones) since it usually depends on the type of the particular compound involved. Contrary to expectations, however, no positive (color) reaction has been found to take place between the used chloroimide reagent and the plurality of ketophenylhydrazones (A), semicarbazones (B), and acylaldehyde hydrazones (C) (6).

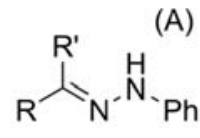

(A)<smiles>[R]C([18F])=NNC(=O)N([R7])C</smiles>

(B)
(C)<smiles>[R]C=NNC(C)=O</smiles>

In order to bear out the validity of all these illations we have initiated a series of tests in which the reactivity of the Gibbs' reagent towards the semicarbazone Nitrofural was investigated.

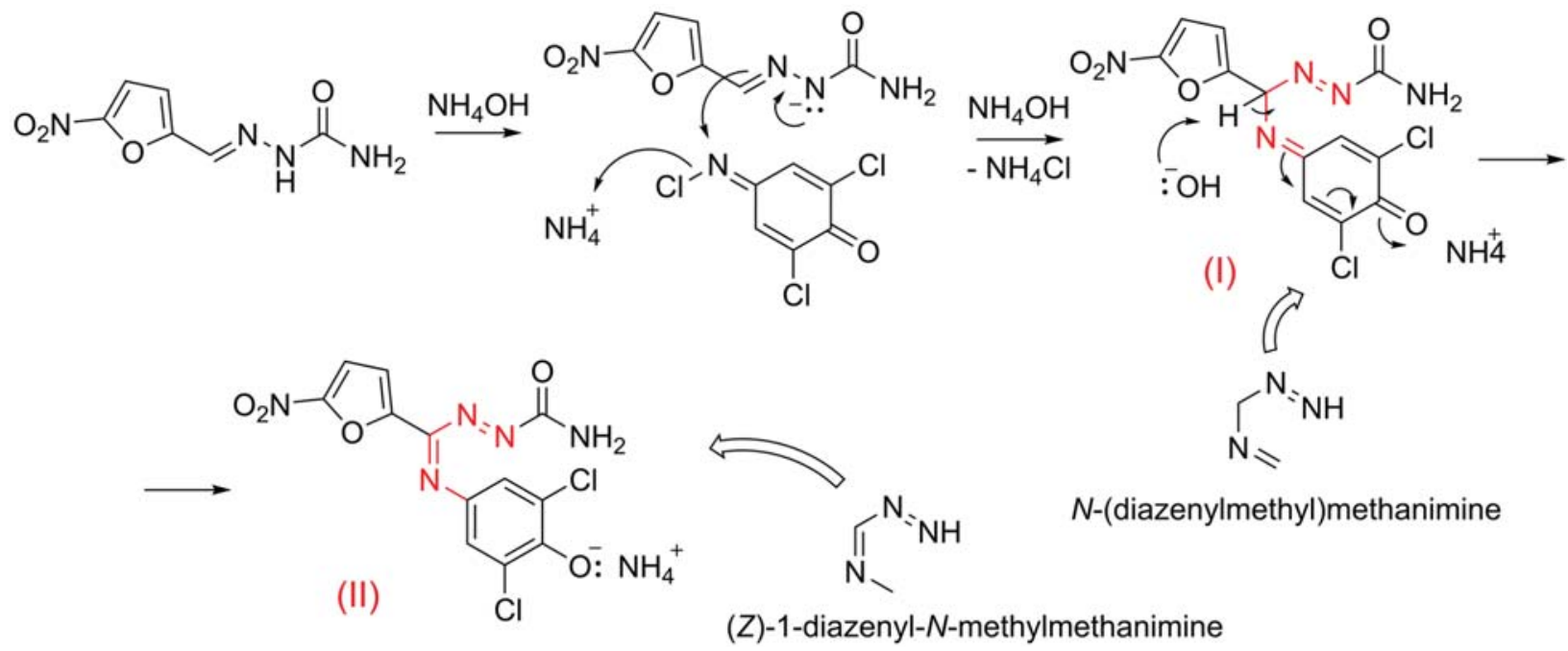

Scheme 1. Proposed mechanism of the reaction between Nitrofural and Gibbs' reagent 
As expected (6), a negative result has been observed in evaporating drops of both reactants ${ }^{4}$. An analogous behavior of the tested semicarbazone toward Gibbs' reagent has also been evinced under solid-phase reaction conditions $s^{5}$.

Inertness of the chloroimide reagent in relation to the tested medicine has likewise been registered both in neutral (AB, Fig.1) and in a weakly acidic organic medium (ABD, Fig.1). Surprisingly, however, in weakly ammoniacal milieu a positive qualitative response (revealed by the appearance of a seaweed green colored product) has been obtained (ABC1, Fig.1). The appearance of a dark seaweed green colored product, very likely, has come as a result of the electrostatic interaction between an easily heterolytically dechalogenated N-haloimide "radical" and the a-aza-stabilized carbanion of the reacting semicarbazone (a carbanion, which can be formed in situ by adding ammonia to the tested weak acidic Nitrofural NH center) (Scheme 1).

This reaction is presumed to proceed through an unstable $\mathrm{N}$-(diazenylmethyl)methanimine, (I) "intermediate", which tends to isomerize to the more stable and green colored 1-diazenyl-N-methylmethanimine product (II).
To exclude the presence of artifacts (complications by side reactions), additional tests were performed in the following order: $\mathrm{AC}, \mathrm{AD}, \mathrm{ABD}, \mathrm{ABE}$, and $\mathrm{AB}$ (for details, see Table 1).

As seen from Fig. 1, DMSO solutions of Nitrofural remain practically unaltered upon the addition of the Gibbs' reagent $(\mathrm{AB}), \mathrm{H}_{2} \mathrm{O}$, and $\mathrm{HCl}$. The same is valid for their mixtures ( $\mathrm{ABD}, \mathrm{ABE})$. In the presence of ammonia (in traces), however, a slight coloring of the Nitrofural solution toward the orange gamma (spectrum) occurred within 3 minutes. No color change was observed toward alkalization of the Gibbs' reagent (AC) all along of the analysis. Again, however, an unexpected stratification of the explored analytical mixture $(\mathrm{AB})$ was observed upon adding an excess $(\geq 0.25 \mathrm{ml})$ of ammonia (cases $\mathrm{ABC}$ and $A B C 2)$. Withal in the course of analysis, a complex set of color changes in the compositions of the obtained phases were also registered.

It is safe to say, a posteriori, that the observed analytical changes (in color and phase) in the two final trials were too involved and complicated to be evaluated analytically and systematically with the required analytical quality.

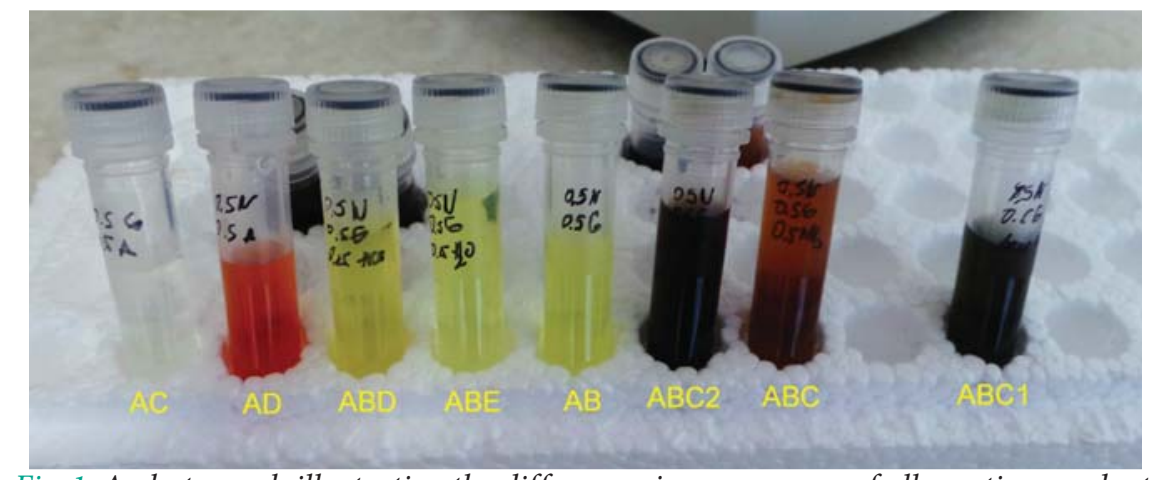

Fig. 1. A photograph illustrating the differences in appearance of all reaction products

At first glance, the mechanism is somewhat astonishing since ammonia is ordinarily not perceived as a classic example for such a strong proton acceptor. However, its action as a base is comprehensible when keeping in mind the behavior of a weak acid that the tested analyte exhibits (2).

\footnotetext{
${ }^{4}$ In this case, anhydrous ethanol was used as resolving and easily volatizing agent for the examined analyte. ${ }^{5}$ Reaction accomplished by gentle rubbing of both reactants with a glass rod on a glass spot plate.
}

\section{UV-Vis Analysis ${ }^{6}$}

The 1-diazenyl-N-methylmethanimine product formation was confirmed by UV-VIS spectroscopy (Fig. 2).

\footnotetext{
${ }^{6}$ The absorption assignments were made by comparing the UV-Vis spectrum of the green coloured product thus obtained $(A B C 1)$ with these of the reaction precursors ( $A$ and $B$ ).
} 


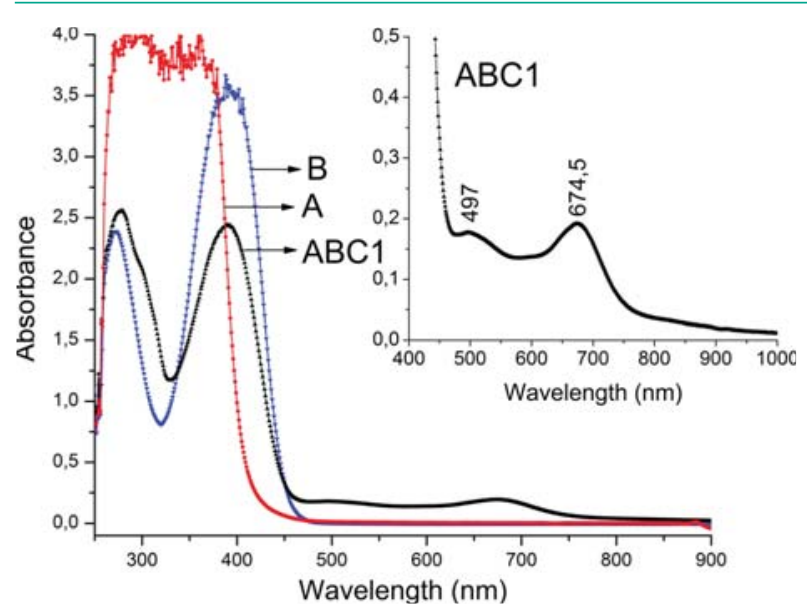

Fig. 2. UV-VIS spectra of the Gibbs reagent (A), Nitrofural (B), and its product of interaction in ammoniacal milieu (ABC1)

As seen from Fig. 2, the UV-Vis spectra of all investigated samples have a similar absorption pattern in the short wavelength (UV) range (from 250 to $330 \mathrm{~nm}$ ). A slight deviation was only registered in the position of the absorption extremum, as well as in the profile (reflected by the appearance of an absorption shoulder at the direction of the red region) of this high energy absorption band in the spectrum of the reaction product $(\mathrm{ABCl})$. The observed spectral effect may be ascribed to the presence of overlapping absorption peaks of the corresponding unreacted reaction species (A and B) - admissible presence of reactants in the composition of the reaction product; it should not be forgotten that the characteristic features of this spot test are manifested toward an insignificant amount of the applied reactants (as it was pointed out supra in traces of ammonia). As regards the absorption peak with a maximum at $440 \mathrm{~nm}$ in the spectrum of the green colored diazenylmethanimine product, no significant deviations from the spectrum of the used Nitrofural substrate (B) have been observed.

The successful inclusion of a chromogenic element into the Nitrofural backbone has been unambiguously proven by the presence of 2 well-defined peaks (with clear and definite shape and maxima) at about 497 and $675 \mathrm{~nm}$ in the spectrum of the formed product. It is suggested that the appearance of these two bands in the spectrum of the compound in question should, most probably, be attributed to the presence of an analyte-specific, extensively conjugated chromophoric system, composed by a compactly arranged (delocalized) double bonds, which are capable of interacting with the electromagnetic radiation in the visible spectral range.<smiles>NC(=O)N=NC(=Nc1cc(Cl)c([OH+])c(Cl)c1)c1ccc([N+](=O)[O-])o1</smiles>

\section{CONCLUSION}

A new, two-step colorimetric test for qualitative determination of Nitrofural using the Gibbs reagent as a chromogenic coupling agent has been successfully developed. In a series of tests, the proposed colorimetric test has proven its reliability and efficiency in the qualitative analysis of the medicine in question. The colorimetric test differs from the existing pharmacopoeial approach in being completely defined by a set of experimental circumstances (factors). The presented method may also be used as experimental proof revealing the hidden possibility of interaction of semicarbazones with the Gibbs reagent. Furthermore, the method employs inexpensive and easily available chemicals. The workflow of the presented procedure is simple, rapid, reproducible, and employable with standard laboratory equipment. It can also be accomplished within the range of the so-called "expressive spot test analysis" by a wide range of investigators even with less analytical experience.

\section{REFERENCES}

1. Pratt WB; Scholar EM. The antimicrobial drugs. New York: Oxford University Press; 2000.

2. European Pharmacopoeia, Strasbourg: Council of Europe. 8th ed., vol. 1 and 2;2013.

3. Pedersen O. Pharmaceutical Chemical Analysis: Methods for identification and limit tests. Boca Raton: Taylor \& Francis Group; 2006.

4. Weygand $\mathrm{C}$, Hilgetag $\mathrm{G}$ (ed. by Hilgetag G. and Martini A.). Preparative Organic Chemistry. John Wiley \& Sons; 1972.

5. Gibbs HD. Phenol tests III. The indophenol test. J Biol Chem. 1927;72(2):649-64. 
Iliyan Kolev, Sonya Ivanova

6. Feigl F, Jungreis E, Oesper RE. Spot tests for phenol vapors and for aromatic compounds containing oxygen. Anal Chem. 1959;31(12):2099-101. doi: 10.1021/ac60156a070.

7. Josephy DP, Damme AV. Reaction of Gibbs reagent with para-substituted phenols. Anal Chem. 1984;56(4):813-14. doi: 10.1021/ac00268a052.

8. Pallagi I, Toró A, Horváth G. Mechanism of the Gibbs Reaction. Part 4. (1) Indophenol formation via n-chlorobenzoquinone imine radical anions. The Aza-S(RN)2 chain reaction mechanism. Chain initiation with 1,4-benzoquinones and cyanide ion. J Org Chem. 1999;64(18): 6530-40.

9. Kramer DN, Gamson RM. Preparation of quinone sulfenimines. J Org Chem. 1959;24(8):1154-5. doi: 10.1021/jo01090a623.

10. Gamson RM, Kramer DN, Miller FM. A study of the physical and chemical properties of the esters of indophenols. II. Structural studies of the isomeric esters. J Org Chem. 1959;24(11):1747-50. doi: 10.1021/jo01093a033.

11. Harfoush AA, Zagloul A, Abdel Halim FM. Kinetics of the reaction of N-2,6-trichlorobenzoquinonimine with sodium thiosulphate. Monatshefte Für Chemie/Chemical Monthly. 1982;113(6-7):837-43. doi: 10.1007/BF00809024.

12. Harfoush AA. Medium effect on the reaction of Gibb's reagent with sodium thiosulphate. J Chem Technol Biotechnol. 1983;33A(6):281-5. doi: 10.1002/jctb.504330602.

13. De Boer EJM, Heijden HVD, Verhoef-Van Wijk WC, Zon AV. Ligands and catalyst systems thereof for ethylene oligomerisation to linear alpha olefins. United States Patent. 2007;Patent No.:US 7,304,159 B2.

14. Kallmayer HJ, Thierfelder B. Die Reaktion Des Iminodibenzyls Mit 2,6-Dichlor-1,4-Benzochinon4-Chlorimid. Pharmazie 2003;58(3):218-9.

15. Annapurna V, Jyothi G, Nagalakshmi V, Sailaja BBV. Spectrophotometric methods for the assay of fluvoxamine using chromogenic reagents. E-Journal of Chemistry 2010;7(4):1539-45. doi: 10.1155/2010/137178.

16. Anger V, Ofri S. Neue Tüpfelreaktionen auf Aldehydphenylhydrazone und Carbonsäurehydrazide mit 2,6-Dichlor-p-benzoehinon-4-chlorimin. Z Anal Chem. 1964;204(4):263-5. doi: 10.1007/ BF00512482.
17. MacManus-Spencer LA, McNeill K. Quantification of singlet oxygen production in the reaction of superoxide with hydrogen peroxide using a selective chemiluminescent probe. J Am Chem Soc. 2005;127(25):8954-5. doi: 10.1021/ja052045b.

18. Gibbs HD. Para-Cresol. A new method of separating paracresol from its isomers and a study of the boiling point. J Am Chem Soc. 1927;49(3):839-44. doi: 10.1021/ja01402a027.

19. Scudi JV. On the colorimetric determination of vitamin B6. J Biol Chem. 1941;139(2):707-20.

20. Scudi JV, Buhs RP. A colorimetric oxidation-reduction method for the determination of the K vitamins. J Biol Chem. 1941;141(2):451-64.

21. Raybin HW. Reaction of theophylline with Gibbs' reagent. J Am Chem Soc. 1945;67(9):1621-2. doi: 10.1021/ja01225a512.

22. Marsh M, Hilty W. Review - Pharmaceuticals and Natural Drugs. Anal Chem. 1955;27(4):636-53.

23. McAllister RA. A New Colour Reaction for Methylthiouracil. Nature 1950;166(4227):789.

24. Adam HK, Douglas EJ, Plummer CF, Cosgrove MB. Estimation of ICI-35868 (Diprivan) in blood by high-performance liquid chromatography, following coupling with Gibbs' reagent. J Chromatogr. 1981;223(1):232-7.

25. Pettigrew MD, Laitenberger PG, Liu B. Analyte detection method. International Patent. 2012; International Publication No.: WO2012049486.

26. Liu B, Pettigrew DM, Bates S, Laitenberger PG, Troughton G. Performance evaluation of a whole blood propofol analyser. J Clin Monit Comput. 2012;26(1):29-36. doi: 10.1007/s10877-011-9330-0.

27. Coop A, Grivas K, Husbands S, Lewis JW. Methylation of the enolates of thevinone and some analogues. Tetrahedron. 1995;51(35):9681-98. doi:10.1016/0040-4020(95)00553-K. 